\title{
Starch to Repress Syneresis of Curdlan Gel
}

\author{
Kin-ichi IsHIDA and Tokuo TAKEUCHI \\ Food Research Institute, Aichi Prefectural Government, \\ Nishi-ku, Nagoya 451, Japan \\ Received November 4, 1980
}

\begin{abstract}
Curdlan gel shrinks even in water caused syneresis. This syneresis is repressed almost completely by the addition of starch to curdlan before heating, but not repressed by the addition of different sugar compounds even of $10 \%$ concentration. The role of starch in repressing syneresis is discussed.
\end{abstract}

Curdlan is a bacterial polysaccharide which is composed mainly of $\beta$-1,3-glucosidic linkage and forms a firm, elastic, heat-irreversible gel when heated in an aqueous suspension at higher than $60^{\circ} \mathrm{C}^{1,2)}$ The gel caused syneresis when it is stored. ${ }^{3)}$ Our previous report ${ }^{4)}$ showed that the syneresis of curdlan gel is decreased by the addition of starch to the gel. The present paper deals with the syneresis of curdlan-starch gel.

\section{MATERIALS AND METHODS}

Materials. Curdlan which was obtained from cultures of Alcaligenes faecalis var. myxogenes was supplied by Takeda Chemical Ind. Ltd. Waxy corn starch from Sanwa Starch Co., maltitol from Nikken Chemical Co. and xylitol from Eisai $C o$. were used. Other materials used were chemically pure-grade reagents.

Preparation of gels. Curdlan is insoluble in cold water but becomes paste nearly at $60^{\circ} \mathrm{C}$. Thus, curdlan gel was prepared as follows. Fifty $\mathrm{ml}$ of an aqueous suspension $\left(30^{\circ} \mathrm{C}\right)$ of curdlan, or a mixture of curdlan and starch, was degassed in vacuo for $20 \mathrm{~min}$ and then $50 \mathrm{ml}$ of boiling water was poured into the suspension and mixed. The temperature of the mixtures was maintained at $55^{\circ} \sim 60^{\circ} \mathrm{C}$. The mixtures were poured into casing tubes $(30 \mathrm{~mm}$ diam.) and were heated in a boiling-water bath for $1 \mathrm{hr}$. Agar gel was prepared by setting the agar sol in casing tube. They were stored at $30^{\circ} \mathrm{C}$. As shown in Fig. 1, moderate syneresis on curdlan gel was observed with the prolonged storage period, so that the gel which was stored for $21 \mathrm{hr}$ was used for experiments in Figs. 2, 3 and Tables I and II.

Measurement of syneresis. After weighing gel with cas ing tube (A), gel was removed from the tube and then the surface of the gel was wiped with filter paper to remove the water released. The gel (B) was weighed. Syneresis $(\%)$ was calculated according to the following equation.

$$
\text { Syneresis }(\%)=\frac{A-(B+\text { weight of casing tube })}{A-\text { weight of casing tube }} \times 100
$$

Measurement of gel strength. A gel was sliced into cylindrical shaped pieces of $20 \mathrm{~mm}$ thickness. Gel strength was measured with a Rheo-meter (Fuji Rika Ind.) and a plunger used was $6 \mathrm{~mm}$ diam.

\section{RESULTS AND DISCUSSION}

Syneresis of curdlan gel was compared with that of agar gel. As shown in Fig. 1, when gels were allowed to stand at $30^{\circ} \mathrm{C}$, syneresis of curdlan gel increased with storage time but that of agar gel did not change. On the other hand, when the sliced gels of $20 \mathrm{~mm}$ thickness were placed on filter paper (Toyo Roshi No. 2 ), syneresis of curdlan gel was less than that of agar gel (Fig. 2).

Effects of various sugar $(10 \%)$ on syneresis and gel strength of curdlan gel $(2 \%)$ are shown in Table I. Except for the gel with waxy corn starch, syneresis of curdlan gel with sugar was a little more than that of curdlan alone. The gel strength of curdlan gel with starch showed the lowest value, while that of gel with sugar was higher than that of curdlan gel. The effect of sugar on the syneresis of gel was inversely that of sugar on the gel strength. Kimura et $a l^{5)}$ reported similar results to our's, but they were not aware of the effectiveness of starch to 


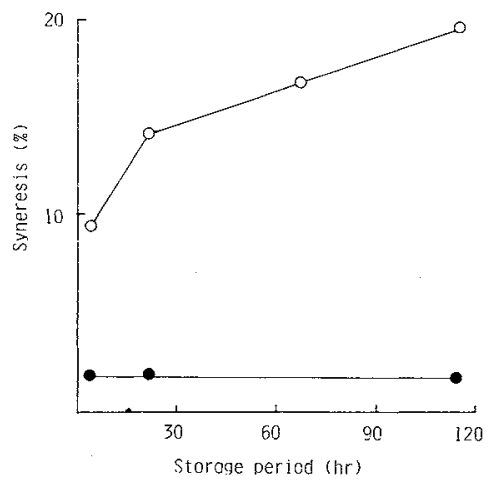

FIG. 1. Comparison of Syneresis of Curdlan Gel (O) and Agar Gel (o) Stored in Casing Tube.

Concentration of curdlan and agar in gel was $2 \%$ respectively. Each gel stored in a casing tube at $30^{\circ} \mathrm{C}$ was removed periodically from the tube and then measured for syneresis.

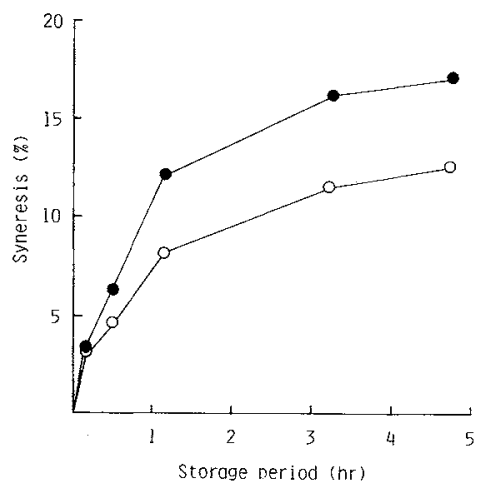

FIG. 2. Comparison of Syneresis of Curdlan Gel ( $O)$ and Agar Gel (O) Placed on Filter Paper.

Concentration of curdlan and agar was the same as in Fig. 1. Each gel was sliced into a cylindrical shape $(30 \mathrm{~mm}$ diam. $\times 20 \mathrm{~mm}$ thickness) and was placed on filter paper at $30^{\circ} \mathrm{C} \mathrm{RH} 80 \%$.

repress syneresis.

The gels with a different ratio of curdlan to waxy corn starch were exmained in syneresis and gel strength. As shown in Fig. 3, syneresis decreases with an increase of starch concentration and reaches a minimum value at more than $5 \%$ of starch. As shown in Fig. 4, gel strength decreases gradually with an increase of starch concentration with each level of curdlan concentration.

Changes of syneresis and gel strength of curdlan gel containing several kinds of raw

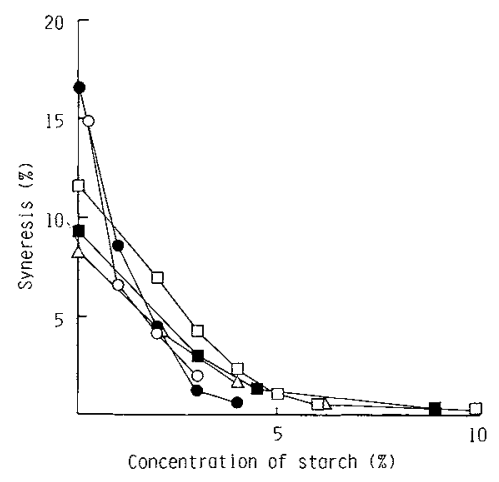

FIG. 3. Effect of Concentration of Waxy Corn Starch on Syneresis of Curdlan Gel.

Concentration of curdlan were as follows: $0,0.5 \%$; $1.0 \% ; \square, 2.0 \% ; \mathbf{\square}, 3.0 \% ; \triangle, 4.0 \%$.

TABle I. EFFECT OF Sugars ON SyNeresis and Gel Strength of Curdlan Gel

Gel contained $2 \%$ of curdlan and $10 \%$ of sugar, respectively.

\begin{tabular}{lcc} 
Sugar & $\begin{array}{c}\text { Syneresis } \\
(\%)\end{array}$ & $\begin{array}{c}\text { Gel strength } \\
\left(\mathrm{g} / \mathrm{cm}^{2}\right)\end{array}$ \\
\hline Fructose & 14.3 & 787 \\
Glucose & 14.1 & 792 \\
Sucrose & 12.6 & 722 \\
Maltose & 13.5 & 764 \\
Glycerol & 17.8 & 821 \\
Xylitol & 17.0 & 778 \\
Sorbitol & 14.2 & 774 \\
Maltitol & 12.6 & 665 \\
Starch* & 0.3 & 328 \\
Control & 13.1 & 707 \\
\hline
\end{tabular}

* Waxy corn starch.

and denaturated starch were examined as shown in Table II. The syneresis of curdlan gel decreases with an increase of potato raw starch, high amylose corn or corn although a decrease of gel strength is observed. Syneresis and strength of gel with soluble starch are not affected.

On a comparison of the syneresis of curdlan and agar gel, the degree of syneresis of the former gel was much higher than that of the latter gel when gel was stored in a casing tube (Fig. 1) but lower when gel was placed on filter paper (Fig. 2). This fact shows that the mechanism of the syneresis of curdlan gel differs 
Table II. EFfect of Various Types of

Starch on Syneresis and Gel

Strength of Curdlan Gel

Gel contained $2 \%$ of curdlan.

\begin{tabular}{lrrr}
\hline Starch & $\begin{array}{c}\text { Concen- } \\
\text { tration } \\
(\%)\end{array}$ & $\begin{array}{c}\text { Syneresis } \\
(\%)\end{array}$ & $\begin{array}{c}\text { Gel } \\
\text { strength } \\
\left(\mathrm{g} / \mathrm{cm}^{2}\right)\end{array}$ \\
\hline Potato & 0 & 10.4 & 527 \\
& 2 & 4.0 & 396 \\
Soluble & 5 & 0.3 & 372 \\
& 10 & 0.1 & 202 \\
& 0 & 10.4 & 527 \\
High amylose & 2 & 9.6 & 545 \\
corn & 5 & 9.7 & 579 \\
& 10 & 14.6 & 524 \\
Corn & 0 & 12.0 & 566 \\
& 2 & 10.6 & 495 \\
& 5 & 6.8 & 460 \\
& 10 & 0.2 & 234 \\
Waxy corn & 0 & 12.0 & 566 \\
& 2 & 6.8 & 361 \\
& 10 & 1.6 & 354 \\
& 2 & 0.3 & 311 \\
& 5 & 6.8 & 481 \\
\hline
\end{tabular}

from that of agar gel. In the case of curdlan gel, syneresis of the gel may be caused by shrinkage and a releasing of water. As shown in Fig. 5, when curdlan gel was stored in distilled water, the gel shrinked during storage and shrinkage was remarkable at the first stage. Changes of shrinkage are similar to that of syneresis. From these results, the function of starch to inhibit the syneresis is considered as follows. On the preparation of gel, raw starch which is surrounded with curdlan sol takes water for swelling during the formation of curdlan gel. This water may have something to do with syneresis. That is, this swelling of the starch granule partially breaks the curdlan gel and inhibits the shrinkage and results in a repressing of the syneresis. Two facts may be offered by way of explanation. First, gel strength and syneresis decrease with an increasing of raw starch concentration. Second, soluble starch which is unable to swell is ineffective and sugar which is unable to take in water is also ineffective. However, interactions between curdlan and starch are not clear; accordingly, further study is

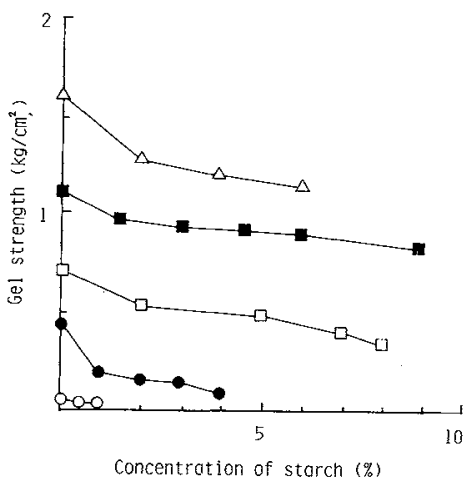

FIG. 4. Effect of Concentration of Waxy Corn Starch on Gel Strength of Curdlan Gel.

Concentration of curdlan were as follows: $0,0.5 \%$; $1.0 \% ; \square, 2.0 \% ; \square, 3.0 \% ; \triangle, 4.0 \%$.

Gel used for measurement was the same as in Fig. 3.

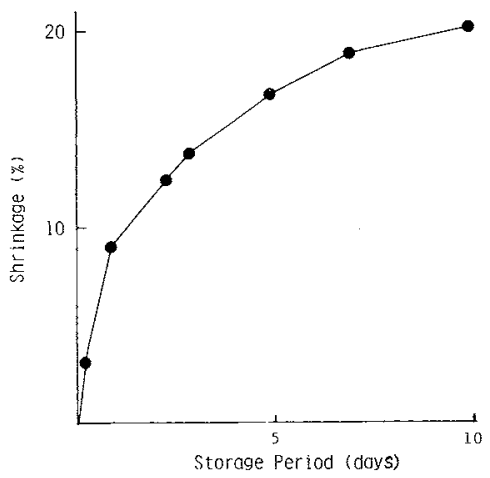

FIG. 5. Changes in Volume of Curdlan Gel during Storage in Distilled Water at $30^{\circ} \mathrm{C}$.

Shrinkage $(\%)$ of gel was expressed as ratio of decreased volume to initial volume of gel.

necessary to explain fully the reason behind this.

Acknowledgments. The authors thank Dr. T. Harada of Institute of Scientific and Industrial Research, Osaka University, and Mr. Y. Koyama, Director of the Food Research Institute, Aichi Prefectural Government, for useful suggestions and encouragement in this research. The authors are also grateful to Takeda Chemical Ind. Ltd. for the supply of curdlan.

\section{REFERENCES}

1) T. Harada, A. Misaki and H. Saito, Arch. Biochem. Biophys., 124, 292 (1968).

2) I. Maeda, H. Saito, M. Masada, A. Hisaki and T. Harada, Agric. Biol. Chem., 31, 1184 (1968). 
3) T. Nakagawa, S. Moritaka and H. Kimura, quoted in T. Harada, "Polysaccharide in Food," ed. by J. M. V. Blanshard and J. R. Mitchell, Butterworths, 1979, p. 283.
4) K. Ishida, I. Shiga and Y. Yokoo, Nippon Shokuhin Kogyo Gakkaishi, 25, 673 (1978).

5) H. Kimura, S. Moritaka and M. Misaki, Food Sci., 38, 668 (1973). 